\title{
Shell Shock; War-Neurosis During World War I
}

\author{
DivyaR ${ }^{1 *}$ and Ashok $\mathbf{V}^{2}$ \\ ${ }^{1}$ Department of Physiology, Karpagam Faculty of medical sciences and research, India \\ ${ }^{2}$ Department of Biochemistry, Karpagam Faculty of medical sciences and research, India
}

*Corresponding author: Divya R, Assistant professor, Department of Physiology,

Karpagam Faculty of medical sciences and research, India.

Received Date: July 03, 2019

Published Date: July 31, 2019

\section{Opinion}

During the First World War, cases of nervous and mental shock began to arrive in England National Hospital for the Paralysed and Epileptic, in Queen Square, London, which was the Britain's leading centre for neurology. "Shell shock" is the term used to address the functional paralyses following shell explosions during warfare. The proximity to explosions in the battlefield was seen as the decisive causative factor for this disorder [1]. These disorders presumed sundry forms and were often tough to differentiate from those instigated by lesions in brain. They include severe or chronic cases of functional neurological disorders that commonly presents as motor syndromes (loss of function or hyperkinesias), every so often united with somato-sensory loss. Psychogenic seizures, anxiety and depression were also reported. These patients also complained of vegetative symptoms such as dizziness palpitations and sweating [2].

\section{Symptoms of shell shock}

Motor disturbances and somatosensory disturbance, Speech such as paralyses of arms or legs, combined with numbness or an altered sensation in the affected area of the body, functional gait disturbences. Involuntary movements such as shaking, tics, functional tremor along with neurosis like choreatic movement (eg; dog chorea) pseudo-seizures, disturbances like aphonia, stutter etc. Visual disturbances such as blindness, diplopia etc. Deafness, Anxiety, depression, dissociative states. Catatonic symptoms, pain and autonomic dysfunctions such as palpitations, shortness of breath, fainting, pericardial pressure, nausea, diarrhoea, bloating incontinence of urine and urgency.

\section{Conclusion}

Research in this field is essential to assess the psychological impact of war-fare on the soldier's mind and its effect on the warveteren's life thereafter.

\section{Acknowledgements}

None.

\section{Conflict of Interest}

No conflict of Interest

\section{References}

1. Linden SC, Jones E, Lees AJ (2013) Shell shock at Queen Square: Lewis Yealland 100 years on. Brain 136(Pt 6): 1976-1988.

2. Linden SC, Jones E (2014) 'Shell shock' revisited: an examination of the case records of the National Hospital in London. Med Hist 58(4): 519545. 